\title{
Impact of barometric pressure on adhesive small bowel obstruction: a retrospective study
}

Yuta Yamamoto* ${ }^{*}$, Yusuke Miyagawa, Masato Kitazawa, Hirokazu Tanaka, Masatsugu Kuroiwa, Nao Hondo, Makoto Koyama, Satoshi Nakamura, Shigeo Tokumaru, Futoshi Muranaka and Yuji Soejima

\begin{abstract}
Background: Adhesive small bowel obstruction (ASBO) is one of the most common causes of postoperative morbidity. According to Boyle's law, decreased barometric pressure expands the volume of intestinal gas. We aimed to elucidate the relationship between barometric pressure and ASBO.

Methods: We divided 215 admissions of 120 patients with ASBO into three groups: the fasting group, which responded to fasting $(n=51)$; the decompression group, which was successfully treated with gastrointestinal decompression $(n=104)$; and the surgery group which required emergency or elective surgery to treat ASBO $(n=$ 60). We compared and examined clinical backgrounds, findings on admission, and barometric pressure during the peri-onset period (29 days: from 14 days before to 14 days after the onset of ASBO).

Results: There were significant differences among the three groups regarding gender, history of ASBO, hospital length of stay, and barometric pressure on the onset day of ASBO. Barometric pressure on the onset day was significantly higher in the fasting group than in the decompression group $(p=0.005)$. During pre-onset day 5 to post-onset day 2 , fluctuations in the barometric pressure in the fasting and decompression groups showed reciprocal changes with a symmetrical axis overlapping the median barometric pressure in Matsumoto City; the fluctuations tapered over time after onset. In the fasting group, the barometric pressure on the onset day was significantly higher than that on preonset days 14, 11, 7, 4, 3, and 2; post-onset days 3 and 10; and the median pressure in Matsumoto City. Conversely, in the decompression group, the barometric pressure on the onset day was lower than that on pre-onset days 14, 5-2; post-onset days 1, 2, 7, 8, 11, 13, and 14; and the median pressure in Matsumoto City. In the surgery group, the barometric pressure on the onset day was equivalent to those on the other days.
\end{abstract}

Conclusions: ASBO with response to conservative treatment is vulnerable to barometric pressure. Additionally, ASBO that is successfully treated with fasting and decompression is associated with a different barometric pressure on the onset day and reciprocal fluctuations in the barometric pressure during the peri-onset period.

Keywords: Adhesive small bowel obstruction, Barometric pressure, Fasting, Decompression, Surgery, Reciprocal fluctuation

\footnotetext{
*Correspondence: yyamamoto@shinshu-u.ac.jp

Division of Gastroenterological, Hepato-Biliary-Pancreatic, Transplantation and Pediatric Surgery, Department of Surgery, Shinshu University School of Medicine, 3-1-1 Asahi, Matsumoto, Nagano 390-8621, Japan
}

(c) The Author(s). 2020 Open Access This article is licensed under a Creative Commons Attribution 4.0 International License, which permits use, sharing, adaptation, distribution and reproduction in any medium or format, as long as you give appropriate credit to the original author(s) and the source, provide a link to the Creative Commons licence, and indicate if changes were made. The images or other third party material in this article are included in the article's Creative Commons licence, unless indicated otherwise in a credit line to the material. If material is not included in the article's Creative Commons licence and your intended use is not permitted by statutory regulation or exceeds the permitted use, you will need to obtain permission directly from the copyright holder. To view a copy of this licence, visit http://creativecommons.org/licenses/by/4.0/. The Creative Commons Public Domain Dedication waiver (http://creativecommons.org/publicdomain/zero/1.0/) applies to the data made available in this article, unless otherwise stated in a credit line to the data. 


\section{Background}

Adhesive small bowel obstruction (ASBO) is one of the most common causes of postoperative morbidity. It occurs in $3 \%$ of all laparotomies; $1 \%$ of patients undergo surgery for ASBO within 1 year after undergoing laparotomy [1-3]. Patients with previous abdominal surgery sometimes develop ASBO despite intentionally consuming easily digestible food and chewing well. Although climate change has been previously reported to be associated with the onset of ASBO [4], it has remained unclear as to whether any other factors other than diet could induce ASBO. The management of ASBO is based on clinical parameters including history, physical examination, laboratory analysis, and computed tomography (CT) imaging. Recent advances in the diagnostic imaging technology of contrast CT have enabled us to accurately identify the findings that indicate intestinal ischemia, including decreased bowel wall enhancement, mesenteric edema, and the closed-loop sign [5-7]. Some patients with ASBO are successfully treated with only fasting, whereas others require intestinal decompression through nasogastric tube (NGT) and long-tube (LT) placement. When conservative management fails, or when patients show signs indicating intestinal ischemia, surgical intervention is necessary. Nevertheless, discrimination of diverse ASBO in respect to the response to each treatment remains unclear.

Several diseases have been reported to be related to barometric pressure, including acute ischemic stroke [8], benign paroxysmal positional vertigo [9], and migraine headache [10]. According to Boyle's law, it is assumed that decreased barometric pressure causes the volume of intestinal gas to expand. Nevertheless, the relationship between ASBO and barometric pressure has not yet been clarified. Therefore, this study aimed to determine the relationship between barometric pressure and ASBO.

\section{Methods}

\section{Patients and study design}

This retrospective cohort study included patients with ASBO who were admitted to Shinshu University Hospital between November 2007 and August 2019. ASBO was diagnosed by clinical symptoms including abdominal pain, nausea, and vomiting, as well as radiological imaging that demonstrated a dilated small intestine with a diameter $>2.5 \mathrm{~cm}$. During the inclusion period, 141 patients (236 admissions) with ASBO were admitted to our department. We excluded 21 admissions of 21 patients who had no history of abdominal surgery. Our final study group consisted of 120 patients (215 admissions) who were divided into three groups: the fasting group, which responded to fasting $(n=51)$; the decompression group, which was successfully treated with gastrointestinal decompression $(n=104)$; and the surgery group, which required emergency or elective surgery to treat ASBO $(n=60)$ (Fig. 1). We compared and examined clinical backgrounds, findings on admission, and barometric pressure during the peri-onset period (29 days: from 14 days before to 14 day after the onset of ASBO). With regard to the management of ASBO, intravenous fluids were administered to all patients. Initially, we assessed the requirement of emergency surgery including strangulation and ischemia or congestion of the small intestine. When these findings were not confirmed, the patients were judged to be candidates for conservative treatment. In general, patients with improving clinical symptoms on admission were managed with fasting in the first $24-48 \mathrm{~h}$. When the obstruction did not improve, they were treated with gastrointestinal decompression including NGT, hyperbaric oxygen therapy (HBO), and LT. Other candidates for conservative treatment with active symptoms were treated with gastrointestinal decompression at first. In cases in which the obstruction continued for more than 1 week, or when the obstruction returned after diet resumption, we performed elective surgery.

Shinshu University Hospital is located in Matsumoto City, Nagano prefecture, almost in the center of Honshu, a main island in Japan, at an altitude of $610 \mathrm{~m}$. Data regarding the average daily barometric pressure in Matsumoto City were obtained from the website of the Japan Meteorological Agency (URL: www.jma.go.jp/jma/index.html). The data were the average of the pressure readings, which were automatically, continuously measured from 0:00 to 24:00 each day using the Automated Meteorological Data Acquisition System at the Matsumoto Meteorological Station.

\section{Statistical analysis}

Statistical analysis was performed using the Statistical Package for the Social Sciences version 23.0 (SPSS; Chicago, IL, USA). Demographic data are presented with descriptive statistics. Non-parametric data are presented as medians with interquartile ranges. With regard to the barometric pressure in each group during the peri-onset period, parametric and non-parametric data were intermingled; thus, we considered all barometric pressure to be non-parametric data. Comparisons between qualitative variables were performed using the Chi-square test. The Kruskal-Wallis test was used to compare non-parametric data among the three groups. If a significant difference $(p<0.05)$ was found, the Mann-Whitney $U$ test with a Bonferroni 


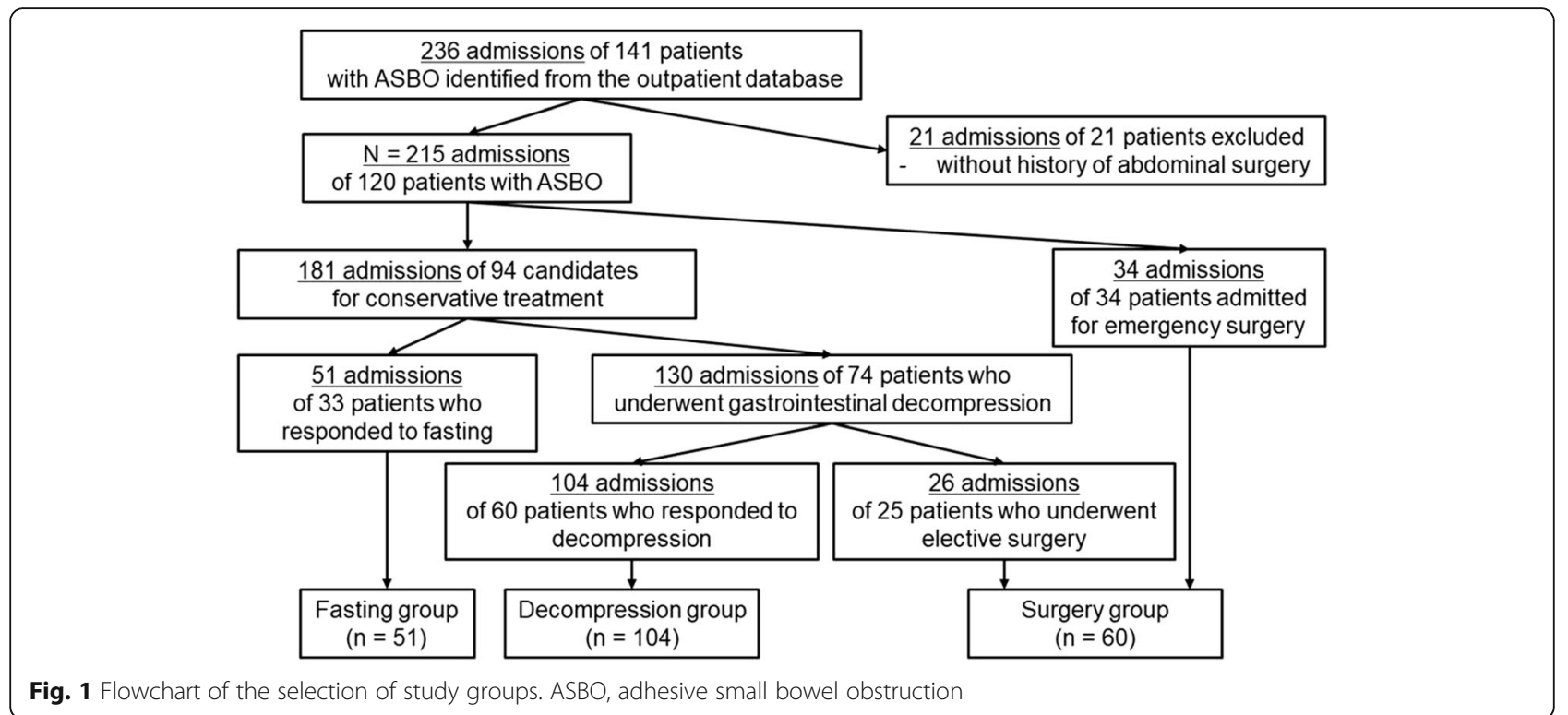

correction for multiple comparisons was used. The Wilcoxon matched-pairs signed-rank test was used to compare the median barometric pressure on the onset day to that on another day in each group. The onesample Wilcoxon signed rank test was used to determine whether a median barometric pressure on a certain day in each group differed from the median barometric pressure in Matsumoto City from November 2007 to August 2019 (943.4 hPa). All tests were two-tailed, and differences with a $p$-value of $<0.05$ were considered statistically significant.

\section{Results}

The characteristics of patients in each group are shown in Additional File 1. There were significant differences among the three groups in terms of gender $(p=0.007)$, history of ASBO $(p<0.001)$, hospital length of stay (LOS) $(p<0.001)$, barometric pressure on pre-onset day $1(p=0.049)$, and on ASBO onset day $(p=0.006)$. As a result of the MannWhitney $U$ test with a Bonferroni correction, LOS was shorter in the fasting group than in the decompression $(p=0.002)$ and surgery groups $(p<$ 0.001 ), and LOS was shorter in the decompression group than in the surgery group $(p<0.001)$. Barometric pressure on the onset day was significantly higher in the fasting group than in the decompression group $(p=0.005)$ (Table 1).

With regard to fluctuation in barometric pressure in each subgroup during the peri-onset period, the line graph shows a reciprocal change in the fasting and decompression groups, in particular from preonset day 5 to post-onset day 2, with a symmetrical axis overlapping the median barometric pressure in Matsumoto City from November 2007 to August 2019 (Fig. 2). In line with this, the barometric pressure on the onset day was significantly higher than those on pre-onset days 4-2 in the fasting group, whereas the pressure on the onset day was lower than those on pre-onset days 5-2 in the decompression group (Table 2). Additionally, these two lines tapered over time after the onset. Compared to the median barometric pressure in Matsumoto City, the pressures on the onset day and post-onset day 1 were

Table $1 P$-values of the Mann-Whitney $U$ test with a Bonferroni correction for multiple comparisons

\begin{tabular}{llll}
\hline & Fasting vs Decompression & Fasting vs Surgery & Decompression vs Surgery \\
\hline $\begin{array}{l}\text { Hospital length of stay } \\
\text { Barometric pressure }\end{array}$ & $0.002^{*}$ & $<0.001^{*}$ & $<0.001^{*}$ \\
Pre-onset day 1 & 0.052 & 1.000 & 0.475 \\
Onset day & $0.005^{*}$ & 0.553 & 0.239 \\
\hline
\end{tabular}

Asterisks indicate statistical significance $(p<0.05)$ 
Fluctuations in Barometric Pressure

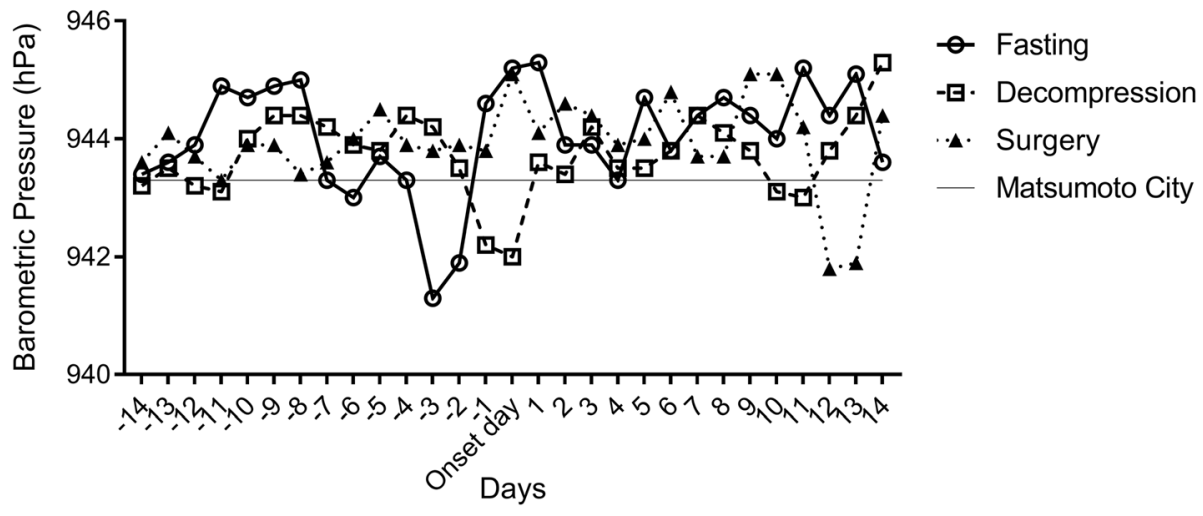

Fig. 2 Fluctuations in the median barometric pressure in each subgroup during the peri-onset period. A horizontal line on $943.4 \mathrm{hPa}$ indicates the median barometric pressure in Matsumoto City from November 2007 to August 2019

significantly higher in the fasting group $(p=0.011$ and 0.008 , respectively), whereas that on the onset day was significantly lower in the decompression group $(p=0.049) \quad$ (Table 3). These findings showed that ASBO, which responds to fasting and decompression, is associated with reciprocal fluctuations in barometric pressure like the sine curve during the peri-onset period, in particular from pre-onset day 5 to postonset day 2, with the amplitude representing significant change in the barometric pressure on the onset day. However, in the surgery group, the barometric pressure on the onset day was equivalent to those on the other days (Table 2) and the median barometric pressure in Matsumoto City (Table 3).

\section{Discussion}

We found that barometric pressure was associated with ASBO which responded to conservative treatment during the peri-onset period. In detail, barometric pressure on the onset day was significantly higher in the fasting group than in the decompression group, and barometric pressures in both groups were significantly different from the median pressure in Matsumoto City. Additionally, the fluctuations in barometric pressure during the peri-onset period in the two groups were significant and reciprocal. When considering the unknown etiology and difficulty of predicting the response and failure of conservative management, these results have significant importance because they suggest the possible impact of barometric pressure on the etiology and treatment of ASBO. Based on our results, observation of the fluctuations in pressure may predict the incidence of $\mathrm{ASBO}$ and response to conservative treatment because of the unique fluctuation during the peri-onset period. Additionally, there is a possibility that patients with ASBO who do not need gastrointestinal decompression treatment can be identified. This is important as it can prevent them from the risk of respiratory complications, as nasogastric decompression significantly increases pneumonia and respiratory failure in patients with ASBO [11].

In Japan, $\mathrm{HBO}$ is regarded as an optional treatment for many diseases which require emergency treatment, including carbon monoxide poisoning, sudden sensorineural hearing loss, central retinal vein occlusion, and ASBO, although few clinical trials have addressed its role in ASBO [12-14]. Based on Boyle's law, decreased barometric pressure causes the intestinal gas volume to expand, and conversely, increases in pressure cause intestinal decompression. Because it remains unclear whether the effect of $\mathrm{HBO}$ on ASBO in humans is cellular, biochemical, or physical in nature, it is difficult to explain the mechanism of our result. However, some animal experiments have been performed [15-17]. In an experiment on dogs that used intestinal closed loop obstructions, Cross reported that, as barometric pressure increased, the absorption of gas from the closed loop obstructions increased in dogs who were breathing in ambient air (i.e., not breathing in a high concentration of oxygen) [18]. In that experiment, an average of $10.4 \%$ of the injected air diffused from the loops after $24 \mathrm{~h}$ at $1 \mathrm{~atm}$ pressure, and $27.0 \%$ was absorbed after the same number of hours at 2 atm pressures, with an increase of $16.6 \%$. Even though natural variation in barometric pressure may have a 
Table 2 Comparison of the barometric pressures between onset and another day in each group

\begin{tabular}{|c|c|c|c|c|c|c|c|c|c|}
\hline & \multicolumn{3}{|l|}{ Fasting group } & \multicolumn{3}{|c|}{ Decompression group } & \multicolumn{3}{|l|}{ Surgery group } \\
\hline & $\begin{array}{l}\text { Barometric } \\
\text { pressure }(\mathrm{hPa})\end{array}$ & $\begin{array}{l}\text { Difference } \\
(\mathrm{hPa})\end{array}$ & $p$-value & $\begin{array}{l}\text { Barometric } \\
\text { pressure }(\mathrm{hPa})\end{array}$ & $\begin{array}{l}\text { Difference } \\
(\mathrm{hPa})\end{array}$ & $p$-value & $\begin{array}{l}\text { Barometric } \\
\text { pressure }(\mathrm{hPa})\end{array}$ & $\begin{array}{l}\text { Difference } \\
(\mathrm{hPa})\end{array}$ & $p$-value \\
\hline Pre-onset day 14 & 943.6 & -1.6 & $0.029^{*}$ & 943.2 & 1.2 & $0.031^{*}$ & 943.6 & -1.5 & 0.363 \\
\hline Pre-onset day 13 & 943.6 & -1.6 & 0.109 & 943.5 & 1.5 & 0.214 & 944.1 & -1.0 & 0.988 \\
\hline Pre-onset day 12 & 943.9 & -1.3 & 0.097 & 943.2 & 1.2 & 0.160 & 943.7 & -1.4 & 0.877 \\
\hline Pre-onset day 11 & 944.9 & -0.3 & $0.047^{*}$ & 943.1 & 1.1 & 0.240 & 943.3 & -1.8 & 0.491 \\
\hline Pre-onset day 10 & 944.7 & -0.5 & 0.211 & 944.0 & 2.0 & 0.080 & 943.9 & -1.2 & 0.697 \\
\hline Pre-onset day 9 & 944.9 & -0.4 & 0.609 & 944.4 & 2.3 & 0.064 & 943.9 & -1.2 & 0.836 \\
\hline Pre-onset day 8 & 945.0 & -0.2 & 0.228 & 944.4 & 2.4 & 0.068 & 943.4 & -1.7 & 0.752 \\
\hline Pre-onset day 7 & 943.3 & -1.9 & $0.041^{*}$ & 944.2 & 2.2 & 0.103 & 943.6 & -1.5 & 0.977 \\
\hline Pre-onset day 6 & 943.0 & -2.3 & 0.087 & 943.9 & 1.9 & 0.159 & 944.0 & -1.1 & 0.563 \\
\hline Pre-onset day 5 & 943.7 & -1.5 & 0.157 & 943.8 & 1.8 & $0.027^{*}$ & 944.5 & -0.6 & 0.683 \\
\hline Pre-onset day 4 & 943.3 & -1.9 & $0.038^{*}$ & 944.4 & 2.4 & $0.003^{*}$ & 943.9 & -1.2 & 0.546 \\
\hline Pre-onset day 3 & 941.3 & -3.9 & $<0.001^{*}$ & 944.2 & 2.2 & $0.009^{*}$ & 943.8 & -1.3 & 0.780 \\
\hline Pre-onset day 2 & 941.9 & -3.4 & $0.013^{*}$ & 943.5 & 1.5 & $0.006^{*}$ & 943.9 & -1.2 & 0.768 \\
\hline Pre-onset day 1 & 944.6 & -0.6 & 0.283 & 942.2 & 0.2 & 0.322 & 943.8 & -1.3 & 0.877 \\
\hline Onset day & 945.2(Control) & - & - & 942.0(Control) & - & - & 945.1(Control) & - & - \\
\hline Post-onset day 1 & 945.3 & 0.1 & 0.970 & 943.6 & 1.5 & $0.024^{*}$ & 944.1 & -1.0 & 0.924 \\
\hline Post-onset day 2 & 943.9 & -1.3 & 0.232 & 943.4 & 1.3 & $0.026^{*}$ & 944.6 & -0.5 & 0.282 \\
\hline Post-onset day 3 & 943.9 & -1.3 & $0.023^{*}$ & 944.2 & 2.1 & 0.062 & 944.4 & -0.7 & 0.688 \\
\hline Post-onset day 4 & 943.3 & -2.0 & 0.063 & 943.5 & 1.5 & 0.167 & 943.9 & -1.2 & 0.724 \\
\hline Post-onset day 5 & 944.7 & -0.5 & 0.066 & 943.5 & 1.5 & 0.287 & 944.0 & -1.1 & 0.831 \\
\hline Post-onset day 6 & 943.8 & -1.5 & 0.060 & 943.8 & 1.8 & 0.192 & 944.8 & -0.3 & 0.473 \\
\hline Post-onset day 7 & 944.4 & -0.9 & 0.065 & 944.4 & 2.3 & $0.019^{*}$ & 943.6 & -1.5 & 0.686 \\
\hline Post-onset day 8 & 944.7 & -0.6 & 0.130 & 944.1 & 2.0 & $0.029^{*}$ & 943.7 & -1.4 & 0.836 \\
\hline Post-onset day 9 & 944.4 & -0.8 & 0.087 & 943.8 & 1.8 & 0.171 & 945.1 & 0.0 & 0.184 \\
\hline Post-onset day 10 & 944.0 & -1.3 & $0.042^{*}$ & 943.1 & 1.0 & 0.067 & 945.1 & 0.0 & 0.132 \\
\hline Post-onset day 11 & 945.6 & 0.4 & 0.357 & 943.0 & 1.0 & $0.013^{*}$ & 944.2 & -0.9 & 0.949 \\
\hline Post-onset day 12 & 944.6 & -0.6 & 0.398 & 943.8 & 1.8 & 0.051 & 941.8 & -3.3 & 0.137 \\
\hline Post-onset day 13 & 945.1 & -0.1 & 0.302 & 944.4 & 2.4 & $0.003^{*}$ & 941.9 & -3.2 & 0.156 \\
\hline Post-onset day 14 & 943.6 & -1.6 & 0.176 & 945.3 & 3.3 & $<0.001^{*}$ & 944.4 & -0.7 & 0.592 \\
\hline
\end{tabular}

Asterisks indicate statistical significance $(p<0.05)$

small impact on the intestinal absorption of gas, the influence of the pressure on ASBO does not simply depend on the physical properties of intestinal gas.

There are several limitations to this study. First, it was a single-center study and therefore may be subject to selection bias. Second, the number of patients was too small to adequately determine the relationship between barometric pressure and ASBO; thus, this may result in a beta error. Third, the parameter that we used did not perfectly represent the exact barometric pressure at specific times and places in patients with ASBO. In particular, not all patients lived in Matsumoto City, and the barometric pressure that we used in this study was the $24 \mathrm{~h}$ mean value; further, we did not consider circadian change. Finally, although we found that barometric pressure affected ASBO in some way, it is still unclear whether the pressure affects the etiology or treatment, or both.

Therefore, prospective multi-center studies incorporating larger patient populations are needed to draw definite conclusions on whether barometric pressure is associated with the etiology and treatment of ASBO. 
Table 3 Barometric pressure comparison between the study groups and the median barometric pressure in Matsumoto City

\begin{tabular}{|c|c|c|c|c|c|c|}
\hline & \multicolumn{2}{|l|}{ Fasting group } & \multicolumn{2}{|l|}{ Decompression group } & \multicolumn{2}{|l|}{ Surgery group } \\
\hline & Barometric pressure (hPa) & $p$-value & Barometric pressure $(\mathrm{hPa})$ & $p$-value & Barometric pressure (hPa) & $p$-value \\
\hline Pre-onset day 14, median (IQR) & 943.6 (939.0-947.0) & 0.564 & $943.2(940.0-948.2)$ & 0.447 & 943.6 (938.9-946.4) & 0.448 \\
\hline Pre-onset day 13, median (IQR) & 943.6 (939.2-948.6) & 0.970 & 943.5 (939.1-947.4) & 0.876 & 944.1 (940.6-946.0) & 0.651 \\
\hline Pre-onset day 12, median (IQR) & $943.9(940.1-947.5)$ & 0.626 & $943.2(940.1-946.6)$ & 0.928 & $943.7(941.2-947.2)$ & 0.383 \\
\hline Pre-onset day 11, median (IQR) & 944.9 (938.9-947.3) & 0.899 & 943.1 (940.0-946.4) & 0.662 & 943.3 (940.1-947.2) & 0.836 \\
\hline Pre-onset day 10, median (IQR) & $944.8(940.7-948.7)$ & 0.158 & $944.0(940.3-947.4)$ & 0.588 & 943.9 (939.5-948.4) & 0.766 \\
\hline Pre-onset day 9, median (IQR) & $945.1(940.7-948.5)$ & 0.076 & $944.4(939.4-947.4)$ & 0.517 & 943.9 (939.9-947.3) & 0.642 \\
\hline Pre-onset day 8, median (IQR) & $945.0(941.0-947.1)$ & 0.212 & 944.4 (939.4-947.8) & 0.513 & 943.4 (940.6-947.8) & 0.303 \\
\hline Pre-onset day 7, median (IQR) & $943.3(938.7-946.7)$ & 0.981 & $944.2(940.1-947.6)$ & 0.433 & $943.6(940.2-947.1)$ & 0.648 \\
\hline Pre-onset day 6, median (IQR) & $943.1(938.7-948.3)$ & 0.910 & 943.9 (939.2-947.8) & 0.879 & $944.0(940.6-947.2)$ & 0.245 \\
\hline Pre-onset day 5, median (IQR) & 943.7 (939.4-947.1) & 0.761 & $943.8(939.5-948.7)$ & 0.521 & 944.5 (939.7-946.9) & 0.664 \\
\hline Pre-onset day 4, median (IQR) & $943.4(938.7-947.4)$ & 0.968 & $944.4(940.0-947.7)$ & 0.181 & 943.9 (940.4-948.4) & 0.433 \\
\hline Pre-onset day 3, median (IQR) & $941.3(936.8-946.6)$ & 0.073 & $944.2(940.2-948.5)$ & 0.179 & 943.8 (938.7-948.1) & 0.889 \\
\hline Pre-onset day 2, median (IQR) & $942.0(939.3-947.6)$ & 0.746 & $943.5(940.2-947.7)$ & 0.357 & 943.9 (938.0-948.2) & 0.892 \\
\hline Pre-onset day 1, median (IQR) & 944.6 (940.9-949.6) & 0.111 & $942.2(938.9-946.2)$ & 0.095 & 943.8 (939.9-947.4) & 0.656 \\
\hline Onset day, median (IQR) & 945.2 (941.9-949.9) & $0.010^{*}$ & $942.0(937.3-946.8)$ & $0.047^{*}$ & 945.1 (938.5-947.6) & 0.642 \\
\hline Post-onset day 1, median (IQR) & 945.3 (940.3-950.4) & $0.024^{*}$ & 943.6 (938.4-946.7) & 0.498 & 944.1 (939.7-947.6) & 0.538 \\
\hline Post-onset day 2, median (IQR) & $943.9(941.0-949.0)$ & 0.131 & 943.4 (939.6-948.1) & 0.827 & 944.6 (940.7-948.3) & 0.166 \\
\hline Post-onset day 3, median (IQR) & $944.0(938.1-947.5)$ & 0.609 & $944.2(939.0-947.4)$ & 0.851 & $944.4(940.7-947.2)$ & 0.317 \\
\hline Post-onset day 4, median (IQR) & $943.3(938.4-947.7)$ & 0.786 & 943.5 (939.6-947.6) & 0.981 & $943.9(939.7-946.9)$ & 0.958 \\
\hline Post-onset day 5, median (IQR) & 945.0 (938.7-947.6) & 0.929 & 943.5 (939.3-947.4) & 0.811 & 944.0 (938.7-947.7) & 0.839 \\
\hline Post-onset day 6, median (IQR) & $944.0(941.0-946.4)$ & 0.677 & $943.8(938.7-946.7)$ & 0.626 & 944.8 (939.4-948.8) & 0.284 \\
\hline Post-onset day 7, median (IQR) & 944.4 (941.4-947.7) & 0.592 & $944.4(940.2-947.2)$ & 0.185 & 943.7 (939.9-949.3) & 0.522 \\
\hline Post-onset day 8, median (IQR) & $944.9(939.6-949.0)$ & 0.494 & $944.1(940.3-947.6)$ & 0.290 & 943.7 (939.3-947.9) & 0.632 \\
\hline Post-onset day 9, median (IQR) & $944.6(938.3-947.6)$ & 0.948 & $943.8(939.8-947.0)$ & 0.957 & $945.1(940.6-948.6)$ & 0.095 \\
\hline Post-onset day 10 , median (IQR) & $944.0(937.2-948.9)$ & 0.859 & $943.1(940.0-946.7)$ & 0.896 & 945.1 (939.3-948.5) & 0.154 \\
\hline Post-onset day 11, median (IQR) & 945.6 (938.9-949.2) & 0.197 & $943.0(940.5-947.0)$ & 0.897 & $944.2(937.8-948.8)$ & 0.721 \\
\hline Post-onset day 12 , median (IQR) & 944.6 (940.7-949.6) & 0.095 & $943.8(939.2-947.9)$ & 0.953 & 941.8 (937.9-948.8) & 0.096 \\
\hline Post-onset day 13 , median (IQR) & $945.1(940.2-948.2)$ & 0.298 & $944.4(939.8-948.3)$ & 0.225 & $941.9(938.6-945.5)$ & 0.101 \\
\hline Post-onset day 14, median (IQR) & 943.6 (940.1-947.8) & 0.466 & $945.3(940.1-949.6)$ & $0.013^{*}$ & $944.4(940.9-947.6)$ & 0.096 \\
\hline
\end{tabular}

Asterisks indicate statistical significance $(p<0.05)$. IQR, interquartile range. The median pressure in Matsumoto City was $943.4 \mathrm{hPa}$

\section{Conclusions}

Barometric pressure on the onset day was significantly higher in the fasting group than in the decompression group. Additionally, the fluctuations in barometric pressure during the peri-onset period in the two groups were significant and reciprocal.

\section{Supplementary information}

Supplementary information accompanies this paper at https://doi.org/10. 1186/s12893-020-00829-1.

Additional file 1. Patients' demographics and summary of data. Patients' demographics and summary of data by study group.

\section{Abbreviations}

ASBO: adhesive small bowel obstruction; CT: computed tomography; NGT: nasogastric tube placement; LT: long-tube placement; HBO: hyperbaric oxygen therapy; LOS: length of stay

\section{Acknowledgements \\ Not applicable.}

\section{Authors' contributions}

YY designed the study, performed the research, acquired the data, and drafted the manuscript. YY, YM, [MK]1, HT, [MK]2, NH, [MK]3, SN, ST, FM, and YS were responsible for the integrity of the data and accuracy of the data analysis. YM and YS revised the manuscript. YY, YM, [MK]1, HT, [MK]2, NH, [MK]3, SN, ST, FM, and YS read and approved the final manuscript. [MK]1 corresponds to Masato Kitazawa, [MK]2 corresponds to Masatsugu Kuroiwa, and $[\mathrm{MK}] 3$ corresponds to Makoto Koyama. 


\section{Funding}

This research received no specific grant from any funding agency in the public, commercial, or not-for-profit sectors.

\section{Availability of data and materials}

The datasets used and/or analyzed during the current study are available from the corresponding author on reasonable request.

\section{Ethics approval and consent to participate}

The study was conducted in accordance with the ethical guidelines of the 1975 Declaration of Helsinki and was approved by the Ethical Committee of Shinshu University Hospital (approval number: 4471). Informed consent was obtained from each patient using the opt-out method; patients could optout at any time on the website. The opt-out method was approved by the Ethical Committee of Shinshu University Hospital.

\section{Consent for publication}

Not applicable.

\section{Competing interests}

The authors declare that they have no competing interests.

Received: 28 May 2020 Accepted: 19 July 2020

Published online: 25 July 2020

\section{References}

1. Ellis $\mathrm{H}$. The clinical significance of adhesions: focus on intestinal obstruction. Eur J Surg Suppl. 1997;577:5-9.

2. ten Broek RP, Issa Y, van Santbrink EJ, Bouvy ND, Kruitwagen RF, Jeekel J, et al. Burden of adhesion in abdominal and pelvic surgery: systematic review and met-analysis. BMJ. 2013;347:f5588.

3. Menzies D. Peritoneal adhesions. Incidence, cause, and prevention. Surg Annu. 1992;24:27-45.

4. Hiki N, Takeshita Y, Kubota K, Tsuji E, Yamaguchi H, Shimizu N, et al. A seasonal variation in the onset of postoperative adhesive small bowel obstruction is related to changes in the climate. Dig Liver Dis. 2004;36:125-9.

5. Balthazar EJ, Birnbaum BA, Megibow AJ, Gordon RB, Whelan CA, Hulnick $\mathrm{DH}$. Closed-loop and strangulating intestinal obstruction: $C T$ signs. Radiology. 1992;185:769-75.

6. Balthazar EJ, Liebeskind ME, Macari M. Intestinal ischemia in patients in whom small bowel obstruction is suspected: evaluation of accuracy, limitations, and clinical implications of CT in diagnosis. Radiology. 1997;205: 519-22.

7. Hayakawa K, Tanikake M, Yoshida S, Yamamoto A, Yamamoto E, Morimoto T. CT findings of small bowel strangulation: the importance of contrast enhancement. Emerg Radiol. 2013;20:3-9.

8. Guan W, Clay SJ, Sloan GJ, Pretlow LG. Effects of barometric pressure and temperature on acute ischemic stroke hospitalization in Augusta, GA. Trans Stroke Res. 2018. https://doi.org/10.1007/s12975-018-0640-0.

9. Korpon JR, Sabo RT, Coelho DH. Barometric pressure and the incidence of benign paroxysmal positional vertigo. Am J Otolaryngol. 2019;40:641-4.

10. Kimoto K, Aiba S, Takashima R, Suzuki K, Takekawa H, Watanabe Y, et al. Influence of barometric pressure in patients with migraine headache. Intern Med. 2011:50:1923-8.

11. Ambiru S, Furuyama N, Kimura F, Himizu H, Yoshidome $H$, Miyazaki $M$, et al. Effect of hyperbaric oxygen therapy on patients with adhesive intestinal obstruction associated with abdominal surgery who have failed to respond to more than 7 days of conservative treatment. Hepatogastroenterology. 2008:55:491-5.

12. Fonseca AL, Schuster KM, Maung AA, Kaplan LJ, Davis KA. Routine nasogastric decompression in small bowel obstruction: is it really necessary? Am Surg. 2013;79:422-8.

13. Fukami Y, Kurumiya Y, Mizuno K, Sekoguchi E, Kobayashi S. Clinical effect of hyperbaric oxygen therapy in adhesive postoperative small bowel obstruction. Br J Surg. 2014;101:433-7.

14. Fukami Y, Kobayashi S, Sekoguchi E, Kurumiya Y. Randomized controlled trial of hyperbaric oxygen therapy in adhesive postoperative small bowel obstruction. Langenbeck's Arch Surg. 2018:403:555-9.

15. Akin ML, Uluutku H, Erenoglu C, Ilicak EN, Elbuken E, Erdemoglu A, et al. Hyperbaric oxygen ameliorates bacterial translocation in rats with mechanical intestinal obstruction. Dis Colon Rectum. 2002;45:967-72.
16. Chen MJ, Chen TY, Cheng YM, Hsu YC. The effect of postoperative hyperbaric oxygen treatment on intra-abdominal adhesions in rats. Int J Mo Sci. 2012;13:12224-31.

17. Bento SV, Nunes TA, Araújo ID, Silva RCOE, Vidigal PVT, Carvalhais RM. Hyperbaric oxygenation on adhesions prevention after laparotomy in rats. Acta Cir Bras. 2018;33:824-33.

18. Cross FS. The effect of increased atmospheric pressures and the inhalation of $95 \%$ oxygen and helium-oxygen mixtures on the viability of the bowel wall and the absorption of gas in closed-loop obstructions. Surgery. 1954; 36:1001-6.

\section{Publisher's Note}

Springer Nature remains neutral with regard to jurisdictional claims in published maps and institutional affiliations.
Ready to submit your research? Choose BMC and benefit from:

- fast, convenient online submission

- thorough peer review by experienced researchers in your field

- rapid publication on acceptance

- support for research data, including large and complex data types

- gold Open Access which fosters wider collaboration and increased citations

- maximum visibility for your research: over $100 \mathrm{M}$ website views per year

At BMC, research is always in progress.

Learn more biomedcentral.com/submission 